\title{
Techno-Economic Evaluation of Power Systems for off- Grid Telecommunications Infrastructure in Remote Locations in Ghana
}

\author{
E. T. Tchao \\ Dept of Computer Engineering \\ Kwame Nkrumah Univ. of \\ Science and Technology
}

\author{
K. A. P Agyekum \\ Dept of Electrical Engineering \\ Kwame Nkrumah Univ. of \\ Science and Technology
}

\author{
Kwasi Diawuo \\ Dept of Electrical Engineering \\ University of Energy and \\ Natural Resources, Sunyani
}

\begin{abstract}
Due to non-existent commercial power, unreliable power supply and high cost of running diesel generators at remote locations in Ghana, it is becoming increasingly uneconomical for network operators to maintain off-grid communication infrastructure at remote locations since subscriber numbers are relatively low in these locations. In order to surmount these challenges, network operators are turning towards the use of alternative power supply systems to power their offgrid infrastructure in these remote areas. This paper seeks to perform a techno-economic evaluation of two commonly used power supply systems for BTS in these remote locations; namely dual prime generators and hybrid power systems. The performance of two off-grid sites using dual prime generators and hybrid power systems have been evaluated at a $100 \%$ site load. The load per day from the two sites was measured as $100 \mathrm{~W}$ on the average. During the evaluation process, it was realized that the hybrid efficiency operates within a $2 \%$ tolerance of the simulated results and provides fuel saving of $61.70 \%$ as compared to the site using dual prime generators at a $100 \%$ site load per day. It was also realized that, the hybrid system has the capability to expand to 5 rectifier modules although the maximum is limited by the size of the generator. With a greater amount of rectification available to increase the rate of recharge for the batteries, it is possible to improve on the reduction in diesel run time and thereby further increase operational expenditure (OPEX) savings to more than $80 \%$.
\end{abstract}

\section{Keywords}

Hybrid Efficiency; Hybrid Power Systems; Renewable Energy Sources; Telecommunications Infrastructure; TechnoEconomic Evaluation

\section{INTRODUCTION}

In many remote areas in many developing countries electric grids are still unavailable. In places where electric grids are available, their reliability is often a major cause of concern for telecom operators [1]. The requirement of a reliable and stable method of power generation is therefore critical to an operator when deploying cell sites, as these requirements have a significant impact on the site's operational costs and the total cost of ownership (TCO) [2]. The non-existent and unreliable electric grid is a critical issue for companies who provide infrastructure and power solutions for network operators in these areas.

The non-existent electric grid coupled with the low user density makes the construction of new base stations not commercially viable [3]. It is therefore unlikely that a network operator will do anything to improve reception in such areas. As a result, the only way to obtain strong cell phone signal in these areas is usually to install an off-grid repeater stations to receive an incoming signal and rebroadcast it after amplifying the signal. An off-grid repeater station is not connected to the public electric grid. In flat rural areas the signal is unlikely to suffer from multipath interference, so it will just be attenuated by the distance. In these cases the installation of a repeater station will increase signal strength to greater distances from the repeater station. Off-grid repeaters are available for all the different GSM and UMTS frequency bands.

The need for finding alternate and efficient sources of energy to power these off-grid telecom infrastructures in remote locations have been discussed in [4-7]. In [4-6], the authors proposed an alternative solution to grid power using the standalone photo voltaic or wind hybrid energy systems with diesel generator as a backup for cellular mobile telephony base station sites in isolated areas. Results in [7] indicated that hybrid energy systems are more cost effective and environmental friendly over the conventional diesel generator. Approximately $70-80 \%$ reduction in fuel cost and the emission of $\mathrm{CO} 2$ and other harmful gasses in environments were achieved. In [8], Picklesimer et al proposed solutions to deal with the challenges of powering remote equipment while controlling both operating costs and energy consumption using an Alternative Power Analyzer (APA) tool specially made for remote base station applications which models the outputs of renewable generated power based on location and user inputs. The authors combined the results with economic inputs to produce a business plan for the implementation of the preferred system. In order for the APA tool to effectively manage complex datasets such as value of assets, duration of deployment and equipment eligibility, a dynamic ontological information framework was developed to iteratively interface with the APA tool. The results of the work indicated that a techno-economic systems approach could be applied both to assess the viability of location-specific system configurations under current incentives frameworks and to inform policy makers in terms of future incentives optimization.

A techno-economic analysis of various stand-alone power systems for the remote base stations have also been done by research studies in [9-12]. The authors in [9-11] evaluated the conventional approach of using diesel generators as a "back up" system and recommended the usage of PEM fuel cells. Results presented in [12] indicated that even with hydrogen technologies market development still lagging behind, some comparable advantages such as high energy conversion efficiency, silent operation and low emissions could be 
achieved and that makes PEM fuel cells a potential candidate for replacing traditional diesel burning generators at remote sites. From a cost of power generation point of view, diesel generators were found to have a slight advantage over PEM fuel cells but uncertain petroleum market and fast developing hydrogen technology market could reverse this trend in the near future [13]. Authors in [13] also pointed out that, long term reliability of PEM fuel cells system still needed to be examined in practice, as this combined with proenvironmental characteristics of fuel cells could make PEM cells usage very useful in pristine and protected areas.

Nfah et al evaluated the optimal power options for 33 remote sites of MTN in Cameroon and presented the results in [14]. Nfah et al indicated that, Photovoltaic hybrid systems (PVHS) with 2 days of energy autonomy is an optimal power options for the supply of the daily energy demands of MTN cell sites at remote locations in Cameroon.

Many network operators in Ghana however still deploy cell sites and repeater stations in rural areas using internalcombustion-engine-driven generator sets. This power supply system is known as dual prime generator option. Two generators set (Gensets) are used with each generator running for a period of 12 hours. Power generated by the diesel generators are; less efficient than public electric grids, increase operational cost, and are also a source of pollution (atmospheric, acoustic) as have been presented in [15].

Due to the numerous advantages network operators in Europe, Asia, America and other parts of Africa are deriving from the use of hybrid power systems at rural areas, a few network operators in Ghana have started using renewable hybrid power systems at remote locations on pilot basis. This hybrid solution combines different but complementary energy generation systems based on renewable energies with a backup of diesel/gasoline Gensets. The hybrid systems capture the best features of each energy resource and can provide "grid-quality" electricity.

This paper seeks to evaluate the dual prime Gensets and hybrid power options usage at off-grid telecom sites in Ghana by carrying out field trial measurements. The results of the field trial measurements and the subsequent evaluation are presented.

\section{POWER SYSTEMS FOR TELECOM INFRASTRUCTURE IN REMOTE AREAS}

Many network operators in Ghana usually use two diesel generators running alternatively (dual prime) as their standard solution via an Automatic Transfer Switch (ATS) to ensure a reliable and stable energy source for network infrastructures in remote areas. This solution is greedy on fossil fuel, has high maintenance requirement and suffer from problems associated with low loading of the diesel engines [16]. The refueling and periodic maintenance of the generators creates logistical problems and results in significant additional expenditure [17].

Following the successes of the hybrid power solutions presented by Nfah et al, some network operators have started deploying hybrid power systems using renewable resources at remote locations in Ghana. This section discusses the hybrid solutions which have been deployed at these pilot sites.

In order to ensure that hybrid systems are the most cost effective, resulting in the best possible total cost of ownership, operators require solutions to be designed such that the different sub-systems such as generators, rectifiers, batteries, solar/wind and controllers are carefully selected and sized to provide the highest possible system efficiency. The architecture of the deployed hybrid system is as shown in Figure 1. This complete Hybrid solution has been designed to be quick and easy to deploy.

The use of a battery technology with a rapid recharge capability and a high level of reliability in the deployed architecture allows for a single diesel generator to be used. This maintains system reliability whilst reducing capital expenditure, with the cost of the battery being covered by the elimination of the second generator in the dual prime generator case. The addition of solar panels enables an increase in cycling time and consequently extends the life of the battery and generator whilst also increasing the environmental benefits. The deployed hybrid solutions are based on a modular design that is both flexible and can easily and swiftly upgrade the number of rectifiers in the field. This will allow the operators to install the basic hybrid system initially to keep deployment costs down and then upgrade when operating cost savings allow for the purchase of renewable elements.

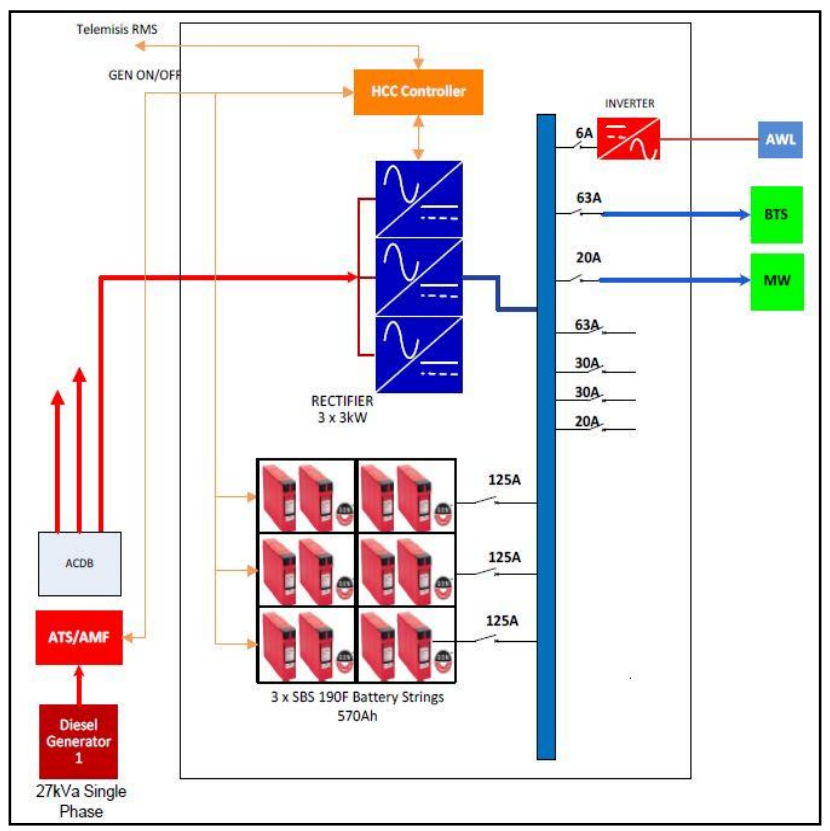

Figure 1: The deployed hybrid system

The power conversion components deliver high efficiency and maximum energy harvest from renewable resources using Maximum Power Point Tracking (MPPT) algorithms. This helps minimizes the power system lifecycle costs and carbon footprint. Majority of hybrid controllers in the market today are basically programmed logic with hour based on/off functions. As site loads are constantly varying, this method of control does not allow for the accurate prediction of battery life based on the number of cycles that are utilised as the cycle life is directly dependent on the depth to which a battery is discharged. The MPPT algorithm for the hybrid controller utilises the counting of the Ampere hours out on discharge and in on recharge. This ensures that the batteries are always discharged to the same state of charge in each cycle ensuring the accurate prediction of battery life. Also the MPPT algorithm ensures accuracy in depth of discharge (DoD) measurements for the solar hybrid. The digital shunt 
measurement is important when the system is operating for a long time without full battery recharge.

The hybrid bus architecture delivers available power from renewable resources supplemented by diesel generator or grid supply when available. The controller logic monitors and maximizes battery lifecycle and minimizes generator runtime to provide best total cost of ownership.

\section{ENERGY CONSUMPTION SIMULATION}

Prior to the field trial measurements at the sites with the two power generation solutions under evaluation, we used certain key information elements from the selected sites to simulate the energy generation and generator runtime using CPS proprietary planning tool. This tool provides the power equipment configuration and a performance prediction with which to compare the end results. The simulation parameters shown in Table 1 are based on the input data provided by the infrastructure management company and the site audit prior to the deployment of two power generation options.

From the simulation parameters, it can be seen that in order to extend the life of the batteries, it will be necessary to run a periodic equalisation charge and this will be taken into account when selecting the battery type in the generator runtime per year simulation. The relationship between the different sources of energy generation over a period of one year with respect to the total site energy requirement for the sites is simulated and shown in Figure 2. Figure 3 details the comparison between the dual prime generator site (site 1), where the generator runs 24/7, and the hybrid solution site (site 2).

From the simulation results, it can be seen that the hybrid solution outperforms the standard solution (dual prime generator) due to the high generator runtime savings achieved by the hybrid solution. This is due to the fact that the photo voltaic batteries are used extensively to provide electrical power to the off-grid system for a period of $16.55 \mathrm{hrs}$ per day as compared to the $24 \mathrm{hrs}$ generator runtime in the dual prime solution. The batteries in the hybrid system store energy for use during the day and when the generator set is working.

Table 1 Simulation parameters

\begin{tabular}{|l|l|}
\hline PARAMETER & VALUE \\
\hline Maximum site load in Watts (DC) & 2000 \\
\hline Maximum site load in Watts (AC) & 1000 \\
\hline Assumed Average load (W) & 1200 \\
\hline Total site load (kWh/yr) & 10512 \\
\hline DIESEL GENERATOR & 8760 \\
\hline Current Genset Run Time (hrs/yr) & 11 \\
\hline Genset Capacity (KVA) & \\
\hline
\end{tabular}

\begin{tabular}{|l|l|}
\hline Genset Phase (Single-100\%/Three-80\%) & $80 \%$ \\
\hline Site Altitude (metres) & 332 \\
\hline Site Maximum Ambient Temperature $\left({ }^{\circ} \mathrm{C}\right)$ & 35 \\
\hline Generator De-rating Factor (\%) & $8.00 \%$ \\
\hline Generator Output (kW) & 8.10 \\
\hline Fuel price per litre (\$llitr) & 1.5 \\
\hline Current litres consumed per hour & 1.5 \\
\hline Generator Service interval (hrs) & 250 \\
\hline Cost per maintenance visit (\$) & 250 \\
\hline BATTERIES & 48 \\
\hline Battery Volts (V) & 30 \\
\hline Battery Operating temperature $\left({ }^{\circ} \mathrm{C}\right)$ & 1.030 \\
\hline Battery Temperature compensation factor & $40 \%$ \\
\hline Depth of discharge (DoD) & 570 \\
\hline Battery Capacity (Ah) & 10.05 \\
\hline Battery Discharge time (hrs) & 4.05 \\
\hline Battery Recharge time (hrs) & 4006 \\
\hline Battery produced power (kWh/yr) & 6535 \\
\hline HYBRID PERFORMANCE & 3.45 \\
\hline New Genset Runtime (hrs/yr) & $68.95 \%$ \\
\hline NewGenset Average runtime per day (hrs) & 59.63 \\
\hline New litres consumed per hour & 67 \\
\hline Genset runtime reduction (\%) & \\
\hline Genset fueling reduction (\%) & \\
\hline Genset produced power (kWh/yr) & \\
\hline
\end{tabular}

\section{FIELD MEASUREMENTS RESULTS AND DISCUSSION}

This section presents and discusses results which were taken during the trial period. The analysis in this section uses a collation of real time data monitored at the two sites under evaluation during the trial period. This gives an accurate reflection of the performance of the systems during the measurement period. The runtime trend results measured readings directly from the hybrid controller to provide consolidated hours run for each element of the solution. For the deployed power solutions, the parameter measurements include the total hybrid runtime, the total battery runtime, the average battery runtime per day, the total generator runtime, the average generator runtime per day and the hybrid efficiency per month. The results of the runtime trend have been summarized in Figures 4-6 and Table 2 
Table 2 Runtime trend results summary

\begin{tabular}{|l|l|l|l|l|l|}
\hline & $\begin{array}{l}\text { Total runtime } \\
\text { hours }\end{array}$ & $\begin{array}{l}\text { Battery runtime } \\
\text { (hours) }\end{array}$ & $\begin{array}{l}\text { Average } \\
\text { battery } \\
\text { runtime per } \\
\text { day (hrs) }\end{array}$ & $\begin{array}{l}\text { Total Genset } \\
\text { runtime (hrs) }\end{array}$ & $\begin{array}{l}\text { Average } \\
\text { Genset runtime } \\
\text { per day (hrs) }\end{array}$ \\
\hline Simulated & 2477.91 & $68.95 \%$ & 16.74 & $31.05 \%$ & 7.26 \\
\hline Measured & 2477.91 & $\begin{array}{l}1728.17 \\
(69.75 \%)\end{array}$ & 16.55 & $749.74(30.25 \%)$ & 7.45 \\
\hline
\end{tabular}

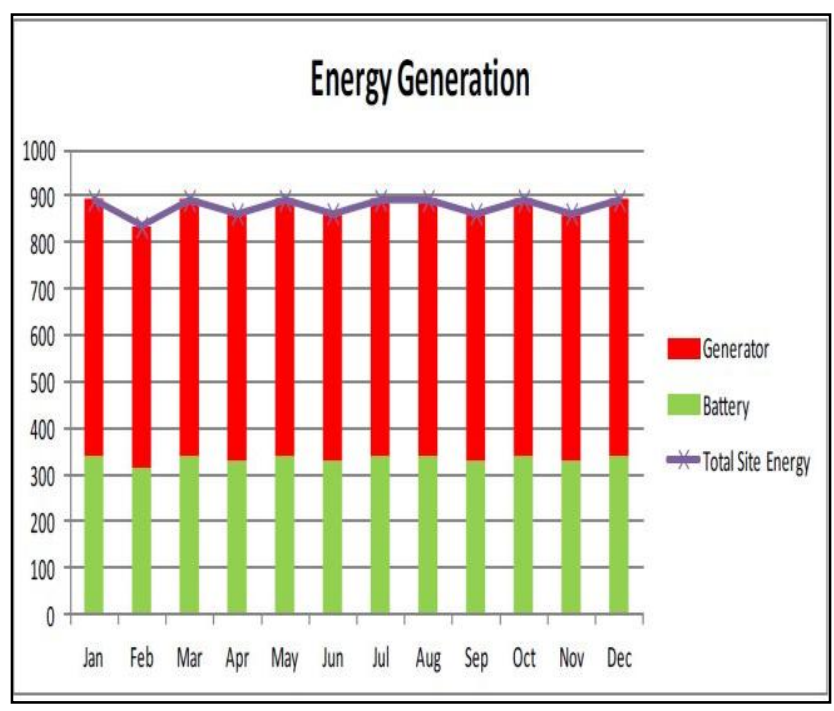

Figure 2 Site energy generation simulation results

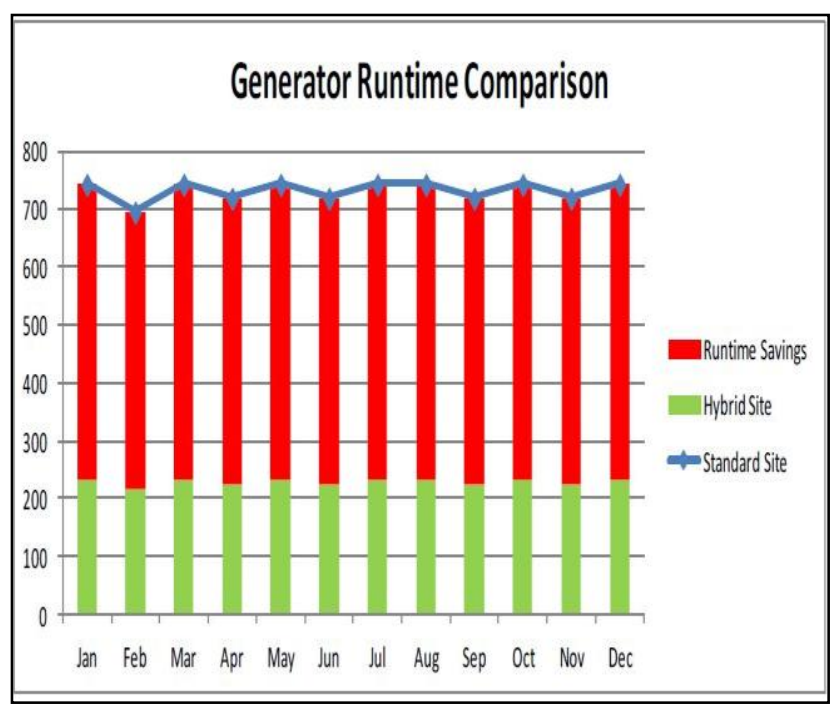

Figure 3 Generator runtime comparison results

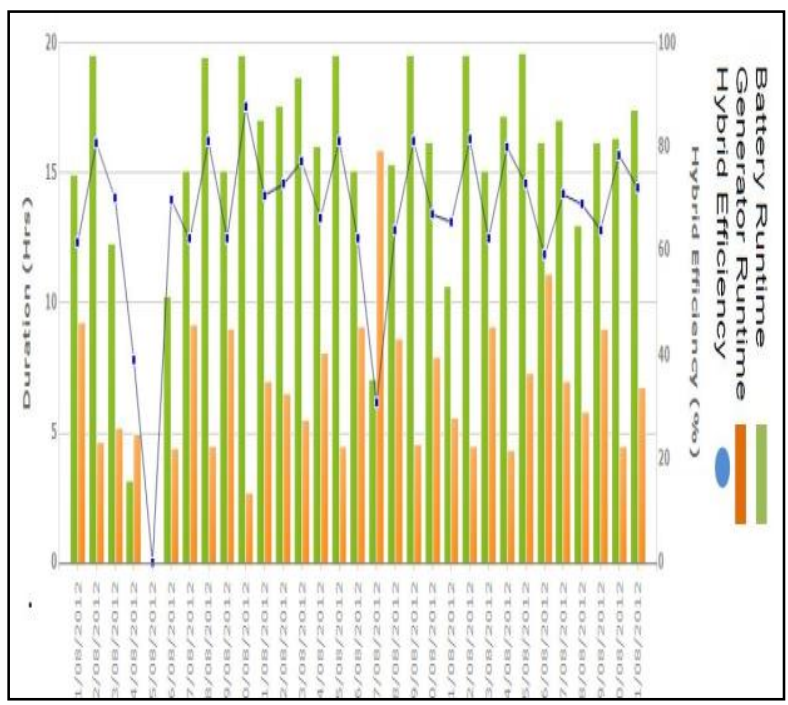

Figure 4 Measured runtime trend for August

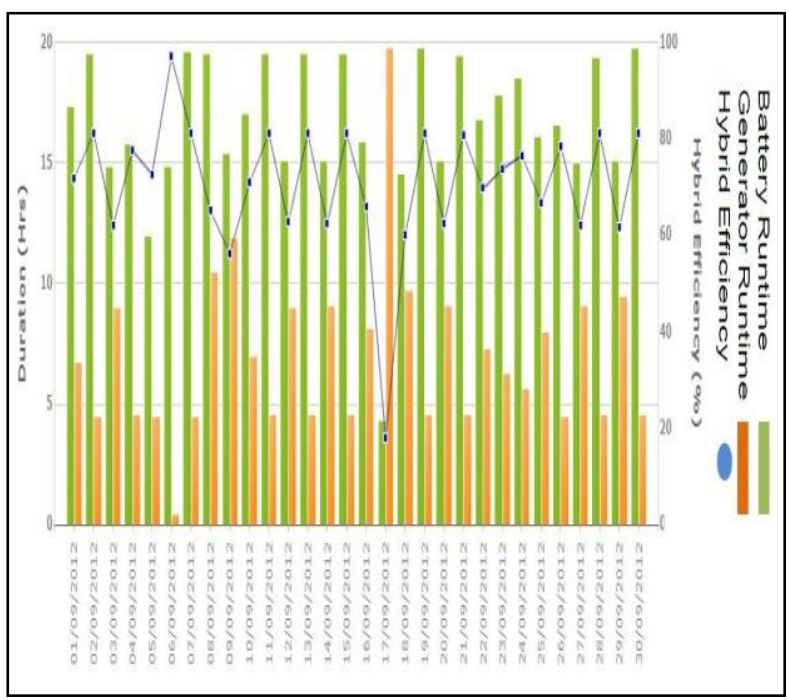

Figure 5 Measured runtime trend for September 


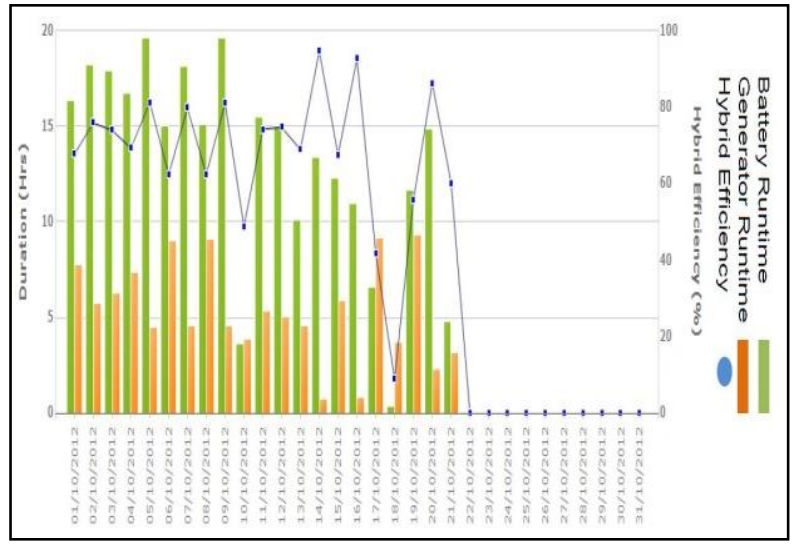

Figure 6 Measured runtime trend for October

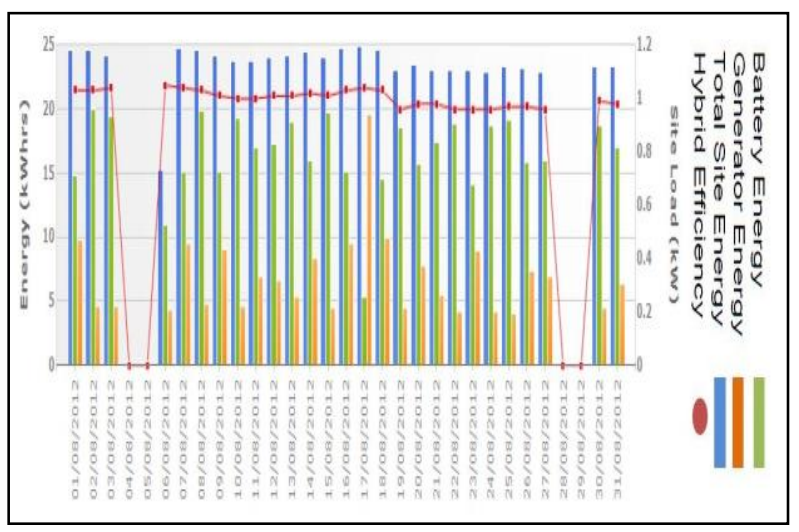

Figure 7 Measured energy trend results for August

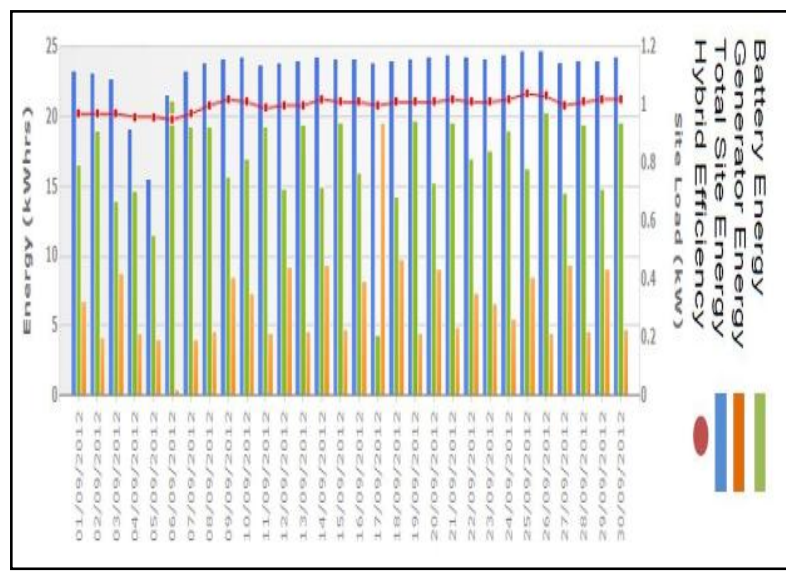

Figure 8 Measured energy trend for September

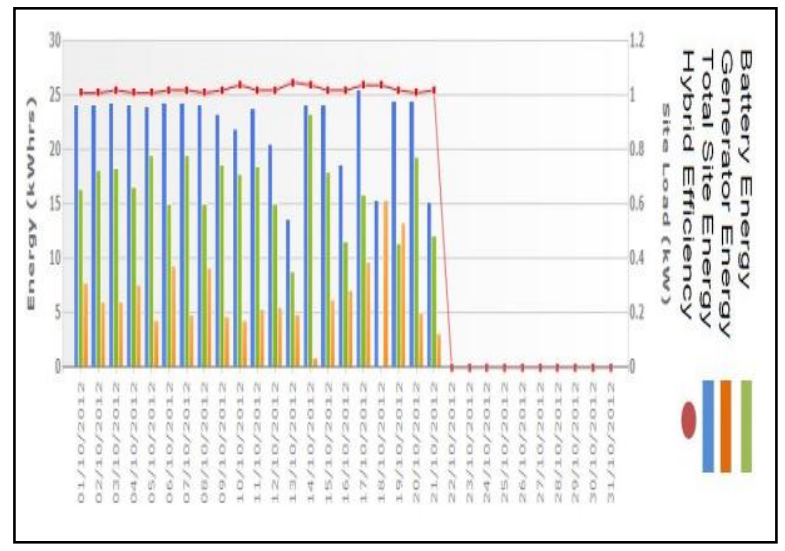

Figure 9 Measured energy trend for October

The energy trend results have been presented in Figures 7-9 and Table 3. From the energy trend results summarized in Table 3, it can be seen that the average site load on the system is $1.12 \mathrm{~kW}$ compared to the simulated load of $1.2 \mathrm{~kW}$.

The fuel usage measurements at the sites and the projected reduction in service cost by showing the extended service interval in days are presented in Table 4 and Table 5 respectively. In order for us to effectively evaluate the fuel savings by the two power generation options, the infrastructure management company provided us with data on the fuel usage at the trial sites. This was confirmed as 1.4litres/hour for 24 hours per day. The usage figures therefore equate to 33.6litres/ day and 235litres per week. Table 4 compares the fuel usage by the two power solutions.

The dual prime diesel generator requires service visit every 250 hours of running which equates to once every 10 days. Table 5 shows the comparison between the service intervals for the sites with the dual generator and hybrid power solutions.

The current service cost is $\$ 250$ per visit and this makes the hybrid solution a better option since there is an increase of 24 days in service interval. With a remote diesel price of $\$ 1.2$ per litre, a general inflation rate of $15 \%$ and a fuel escalation of $11 \%$, the hybrid solution can be designed to achieving an operational savings of $80 \%$ by increasing the number of rectifiers from 3 to 5 to optimize the battery recharge process. This will help reduce the generator runtime in the hybrid solution and reduce the fuel cost

\section{CONCLUSION}

The paper has evaluated the two power options used by network operators in Ghana. Results discussed in the paper have demonstrated the reduction in diesel generator runtime of off-grid sites with a runtime savings of 16.55 hours achieved using a hybrid solution. Reduction of OPEX costs associated with the dual prime diesel generator which includes; fuel cost, passive maintenance costs and active maintenance costs have been achieved using a hybrid power solution. An operational time of the diesel generator in the range 7.45 hours per day with hybrid efficiency and $\mathrm{CO} 2$ emission savings of $69.75 \%$ and $61.70 \%$ respectively have also been achieved using hybrid power solutions with renewable resources.

\section{REFERENCES}

[1] D. Kammen, "Promoting appropriate energy 
technologies in the developing world," Journal of Environmental sciences, vol. 41, no. 5, pp. 11-15, 34-41, 1999.

[2] Bartholf, T.R. "An economic analysis of power system designs for remote site telecommunications applications" in proceedings of Telecommunications Energy Conference, June 1988, pp. 472 - 474

[3] Brenier, A.; Mahe, L.; Green, A. "Financial strategies for backup power in telecom networks" 22nd International Conference on Communication, Networking \& Broadcasting, Sept 2000, pp. $135-143$

[4] Kaldellis J.K., Ninou I., Zafirakis., "Minimum long-term cost solution for remote telecommunication stations on the basis of photovoltaic-based hybrid power systems" journal on Energy Policy, Vol. 39, Issue 5, May 2011, Pp 2512-2527

[5] Kanzumba Kusakana and Herman Jacobus V. "Hybrid renewable power systems for mobile telephony base stations in developing countries" Renewable Energy, Vol. 51, March 2013, Pp. 419-425

[6] Bajpai, P.; Prakshan, N.P.; Kishore, N.K. "Renewable hybrid stand-alone telecom power system modeling and analysis" in Proc. of IEEE Region 10 Conference on Communication, Networking \& Broadcasting, April 2009 , pp. $32-45$.

[7] Mangu, B.; Kumar, K.K.; Fernandes, B.G. "A novel grid interactive hybrid power supply system for telecom application" In proceedings of India Conference on Communication and networking systems, Feb, 2011, pp. $232-237$.

[8] Picklesimer, D.; Rowley, P.; Parish, D.; Carroll, S.; Bojja, H.; Whitley, J.N. "Techno-economic optimization of sustainable power for telecommunications facilities using a systems approach", in Proceedings of the 2010 IEEE International Symposium on Communication, Networking \& Broadcasting, May 2010, pp $23-28$

[9] Dario B., Frano B., Ivan T., “Techno-economic analysis of PEM fuel cells role in photovoltaic-based systems for the remote base stations" International Journal of Hydrogen Energy, Vol. 38, Issue 1, 11 January 2013, Pp

\section{$417-425$}

[10] Butler D.: "Requirements for batteries in remote-area power-supply systems based on technical modelling and field experience" Journal of Power Sources, Vol. 59, Issues 1-2, March-April 1996, pp. 99-105.

[11] Lubritto, C.; Petraglia, A.; Vetromile, C.; Caterina, F.; D'Onofrio, A.; Logorelli, M.; Marsico, G.; Curcuruto, S., "Telecommunication power systems: Energy saving, renewable sources and environmental monitoring" In proceedings of the 30th IEEE International Conference on Communication, Networking \& Broadcasting INTEC 2008, pp. $1-4$

[12] Gahrn, Viggo; Mueller, Mogens P.; Schlosser, Hans G. "Power Supply Systems for Remote, Unmanned Microwave Repeater Stations in Greenland" Telecommunications Energy Conference, Feb 1987., pp. $321-326$

[13] V. A. Ani, "Optimal energy system for single household in Nigeria", International Journal of Energy Optimization and Engineering, vol. 2, no. 3, pages 26-32, 2013.

[14] Nfah E.M., Ngundam J.M., "Evaluation of optimal power options for base transceiver stations of Mobile Telephone Networks Cameroon" Journal on Solar Energy, Vol. 86, Issue 10, October 2012, pp. 2935-2949

[15] Pragya N., Nema R.K., Saroj R., "Minimization of green house gases emission by using hybrid energy system for telephony base station site application" Renewable and Sustainable Energy Reviews, Vol. 14, Issue 6, August 2010, pp 1635-1639

[16] Kaldellis J.K., Ioanna N., "Energy balance analysis of combined photovoltaic-diesel powered telecommunication stations" International Journal of Electrical Power \& Energy Systems, Vol. 33, Issue 10, December 2011, pp 1739-1749.

[17] Chowdhury, S.A.; Aziz, S., "Solar-diesel hybrid energy model for Base Transceiver Station (BTS) of mobile phone operators" 2nd International Conference on Communication, Networking \& Broadcasting: Developments in Renewable Energy Technology (ICDRET), Feb 2012, pp. 1 - 6 . 